\title{
Vulnerabilidade do Comércio Agrícola Brasileiro
}

\author{
Maria Auxiliadora de Carvalho ${ }^{1}$ \\ César Roberto Leite da Silva ${ }^{2}$
}

Resumo: A dívida externa elevada e o déficit crônico em transações correntes obrigam o Brasil a produzir superávits comerciais significativos. A agricultura tem dado uma grande contribuição, dado que o valor de suas exportações vem crescendo a taxas mais elevadas que a dos demais produtos, resultando num bem vindo superávit comercial agrícola. Entretanto, apoiar-se na agricultura como principal fonte de divisas coloca o país numa situação de vulnerabilidade: a demanda mundial por produtos agrícolas é relativamente decrescente, a variabilidade dos preços e quantidades do comércio agrícola é bem maior do que a dos produtos industrializados, e as relações de troca das exportações agrícolas têm declinado nos últimos 30 anos. Esses fatos levam a concluir que as razões que levaram à adoção do modelo de substituição de importações voltaram a ser pertinentes na atualidade e que o aumento das quantidades exportadas de produtos agrícolas não necessariamente significa melhoria do bem estar da sociedade brasileira.

Palavras-chave: relações de troca, agricultura, vulnerabilidade externa

Classificação JEL: Q17

\footnotetext{
${ }^{1}$ Doutora em Economia de Empresas / Pesquisadora do Instituto de Economia Agrícola. macarvalho@iea.sp.gov.br

2 Doutor em Ciências Econômicas / Pesquisador do Instituto de Economia Agrícola / Professor da PUCSP. crlsilva@iea.sp.gov.br
} 
Abstract: The high foreign debt and the chronic current account deficit force Brazil to produce significant trade surplus. Agriculture has been giving a great contribution as its export value has been growing at higher rates than economy other products; therefore there is a welcome agricultural trade surplus. However, to depend on agriculture as main source of exchange value puts the country in a vulnerable situation: the world demand for agricultural products is relatively decreasing, the agricultural trade prices and amounts variability are bigger than of industrialized products, and the agricultural terms of trade have been declining in the last 30 years. Such facts enable the conclusion that the justification of the substitution of imports model is pertinent again and that the increase in export amounts of agricultural products not necessarily imply the Brazilians welfare improvement.

Key-words: terms of trade, agriculture, external vulnerability.

\section{JEL Classification: Q17}

\section{Introdução}

A literatura registra que a vulnerabilidade externa é a maior fragilidade da economia brasileira desde os seus primórdios. A Comissão Econômica para a América Latina e Caribe (CEPAL), já na década de 1940 diagnosticou que a maior causa das dificuldades da América Latina no setor externo era que a entrada de divisas dependia das exportações de poucos produtos primários. Esse diagnóstico é de Prebisch (1949), baseado em estudo das NAÇÕES UNIDAS (1949) que mostrava a tendência secular ao declínio das relações de troca do continente, tradicional exportador de produtos primários e importador de industrializados, e inferia que a região estava fadada ao permanente subdesenvolvimento caso não fossem tomadas medidas positivas para reverter essa tendência. Como o problema estava na especialização em produtos primários, o governo deveria interferir no processo criando barreiras à importação e infra-estrutura básica para impulsionar a industrialização.

O Brasil, já em 1930, premido pelo estrangulamento externo causado pela queda dos preços do café, havia intensificado sua industrialização pelo processo de substituição de importações. Grosso modo, pode-se dizer que 
até o final da II Guerra Mundial as autoridades brasileiras reagiam às crises externas desvalorizando a taxa de câmbio, o que estimulava a produção doméstica de manufaturados. Mas, a partir de 1945 pode-se notar uma política deliberada de industrialização, na qual a política cambial era apenas um dos vetores, ao lado da re-configuração do arcabouço institucional, investimentos em infra-estrutura e fornecimento de insumos básicos, que eram produzidos essencialmente por empresas estatais criadas para este fim (VASCONCELLOS; GREMAUD \& TONETO JR., 1999). Visto de outra forma, a partir desta época, o Estado impôs sua presença na economia brasileira.

Ao longo de pouco mais de meio século de crescente inserção do governo na economia brasileira e de práticas protecionistas rigorosas com vistas ao desenvolvimento por substituição de importações, o país transformou significativamente sua estrutura produtiva: de uma economia primário-exportadora tornou-se uma sociedade predominantemente urbana e industrial. Nesse sentido pode-se dizer que a estratégia foi bem sucedida. No entanto, o objetivo central do modelo era reduzir a vulnerabilidade do país às mudanças cíclicas das economias centrais. Nesse particular não se pode dizer que houve sucesso. Pelo contrário, essa estratégia resultou em forte endividamento externo, cujas implicações forçaram o rompimento do modelo rumo à ampla liberalização comercial na década de 1990 .

Com a liberalização comercial, e a apreciação do câmbio ocorrida na primeira fase do plano Real, a balança comercial brasileira, tradicionalmente superavitária, começou a registrar déficits a partir de 1995, situação que só foi revertida em 2001, graças sobretudo à mudança na política cambial ocorrida em 1999. Os déficits comerciais agravaram o já crônico déficit em transações correntes, cujo financiamento foi feito por investimentos diretos estrangeiros, empréstimos e financiamentos. Essas modalidades de entrada de capital acarretaram remessas de lucros e pagamentos de juros que, por sua vez, contribuíram para a formação de novos déficits. Se as exportações não propiciarem as divisas necessárias para efetuar essas remessas, aumentarão o endividamento e as possibilidades de ocorrência de novas crises no balanço de pagamentos.

Nota-se que o setor agrícola vem contribuindo expressivamente para a provisão de divisas. No entanto, depender dessa fonte gera intranqüilidade por pelo menos duas razões. A primeira é a elevada concentração das exportações agrícolas em poucos produtos, o que amplia a variabili- 
dade do ingresso de divisas. A segunda é a tendência de crescimento da participação dos produtos básicos no Produto Interno Bruto (PIB) e no comércio, obstáculo ao desenvolvimento que o modelo de substituição de importações pretendeu superar.

Para argumentar a favor destas questões, este trabalho procura, inicialmente, mostrar a relação entre necessidade de divisas e crescimento econômico para a economia brasileira. Em seguida discute a contribuição da agricultura na composição do PIB e no comércio exterior, e confronta estatísticas de variabilidade, concentração, bem como da evolução dos termos de troca do setor agrícola brasileiro nas últimas décadas. Ao final considera que a crescente dependência das exportações agrícolas põe em risco a capacidade de geração de divisas do país, bem como a possibilidade de alcançar o crescimento econômico sustentado.

\section{Crescimento econômico e necessidade de divisas}

Segundo o enfoque tradicional do balanço de pagamentos, o saldo do comércio de bens e serviços depende das taxas de crescimento local e mundial e da taxa de câmbio real. Partindo de uma situação de equilíbrio comercial, para uma dada taxa de crescimento local, mantidas as outras variáveis constantes, quanto maior for a elasticidade renda das importações $\left(\eta_{M}\right)$, maior a necessidade de divisas para pagá-las. Supondo que a elasticidade das importações seja 1, um aumento de 1\% no PIB acresce as importações nesse mesmo percentual e, para equilíbrio comercial, as exportações também precisariam crescer $1 \%$.

A partir desse raciocínio, um simples exercício numérico permite avaliar a dimensão das necessidades de divisas da economia brasileira. Observouse elasticidade média das importações de 0,9 entre 1990-94, de 1,4 entre 1995-99 e de 0,8 entre 2000-02. A média para todo o período foi 1,1 e significa que para cada $1 \%$ de crescimento do PIB o valor das importações cresceu em $1,1 \%{ }^{3}$. Como entre 1990 e 2002 o PIB brasileiro expresso em dólares cresceu, em termos médios anuais, $2,1 \%$, as exportações deveriam

\footnotetext{
${ }^{3}$ Esses dados foram calculados a partir dos valores das importações e do PIB brasileiros disponíveis em http://www.ipeadata.gov.br, acesso em 29/03/04. MARQUEZ (1990) estimou em 0,40 a elasticidade renda das importações para os países menos desenvolvidos no período 1973 a 1985.
} 
ter crescido 2,3\%a.a. simplesmente para manter a situação anterior. Na realidade a média anual de crescimento das exportações foi de 4,7\% no período, mais que suficiente para cobrir o acréscimo das despesas com importações, resultando em diferença positiva de 2,4\%a.a. (Tabela 1).

Tabela 1. Taxa média anual de crescimento do comércio e do PIB e elasticidade das importações, Brasil, 1990-2002

\begin{tabular}{lcccccc}
\hline \multirow{2}{*}{ Período } & PIB ( $\left.{ }^{1}\right)$ & \multicolumn{3}{c}{ Importação } & \multicolumn{3}{c}{ Exportação (\%) (1) } \\
\cline { 3 - 7 } & $(\%)$ & $\%\left({ }^{1}\right)$ & Elasticidade $\left(^{2}\right)$ & Observada & Necessária $\left({ }^{3}\right)$ & Diferença \\
& $(1)$ & $(2)$ & $(3)$ & $(3)$ & $(4)$ & $(5)$ \\
\hline $1990-94$ & 6,4 & 13,3 & 0,9 & 5,2 & 6,0 & $-0,8$ \\
$1995-99$ & 1,9 & 10,3 & 1,4 & 2,2 & 2,8 & $-0,6$ \\
$2000-02$ & $-4,9$ & $-0,7$ & 0,8 & 8,0 & $-3,9$ & 11,8 \\
$1990-02$ & 2,1 & 8,9 & 1,1 & 4,7 & 2,3 & 2,4 \\
\hline
\end{tabular}

(1) Média de variação do valor expresso em dólar

( $\left.{ }^{2}\right)$ Média de $(\Delta M / M) /(\Delta Y / Y)$, onde $M=$ importação e $Y=$ PIB, ambos expressos em dólar.

$\left({ }^{3}\right)(4)=(1) *(3)=$ taxa de crescimento da exportação necessária para manter a situação inicial Fonte de dados básicos: IPEADATA, acesso em 29/03/04

A análise por subperíodo mostra que essa diferença positiva deve-se ao bom desempenho da balança comercial dos 3 últimos anos, ocasião em que o crescimento médio das exportações superou as necessidades em $11,8 \%$, não tanto pelo aumento das exportações, que foi de 8,0\%, mas pelo declínio do PIB expresso em dólar, à taxa média anual de $4,9 \%{ }^{4}$.

Na maior parte da década de 1990 as divisas obtidas com exportações não foram suficientes sequer para equilibrar a balança comercial. As necessidades de divisas não se restringem ao pagamento das despesas com importações. Elas são necessárias para cobrir o saldo de todas as transações correntes do balanço de pagamentos (TC) que, além da balança comercial, englobam o balanço de serviços, o balanço de rendas e as transferências unilaterais. $\mathrm{O}$ saldo de TC mostra, portanto, as diferenças entre pagamentos e recebimentos pelas transações com bens, serviços e fatores de produção ao longo de determinado tempo, e se for negativo significa que as transações provocaram mais saídas que entradas de divisas.

${ }^{4}$ Esse decréscimo do valor do PIB em dólar se deve à desvalorização da moeda brasileira. No período a média de variação real do PIB foi de 2,5\% (IBGE, 2004) 
As estatísticas brasileiras levantadas sistematicamente vão de 1947 a 2003. Nesses 56 anos de levantamento em 17 deles houve déficit comercial, mas as transações correntes apresentaram déficit em 49. As causas disso são os saldos dos balanços de serviços e de rendas, que não registraram saldos positivos sequer uma vez nesse período. O problema é que o déficit em transações correntes de determinado ano, financiado com recursos captados no exterior, gera pagamentos futuros de juros e lucros que vão compor o balanço de rendas e a formação de novos déficits em transações correntes nos períodos subseqüentes.

A década de 1990 deu contribuição expressiva para a manutenção da dependência externa brasileira. Na média do período 1991-2000 as exportações cobriram somente $72,2 \%$ das despesas a pagar. As transferências unilaterais correntes responderam por mais 4,0\% resultando que $23,8 \%$ dos gastos realizados no exterior foram financiados com recursos externos. A dívida externa total registrada, que era de US\$ 123,4 bilhões em 1990 passou para US\$236,2 bilhões em 2000, com crescimento de mais de $90 \%{ }^{5}$. O auge do endividamento aconteceu em 1997 e 1998, anos em que os déficits das transações correntes ultrapassaram US $\$ 30$ bilhões. Com isso, as remessas de rendas, que no começo da década giravam em torno de US $\$ 10$ bilhões, passaram para US \$ 14,9 bilhões em 1997 e para US\$ 18 bilhões a US \$ 20 bilhões nos últimos 6 anos.

A obrigação de pagar rendas deve permanecer dessa ordem pelos próximos anos se a maior parte da dívida não for amortizada. Isso implica que, mesmo na ausência de crescimento econômico, o país precisa gerar superávit comercial para honrar esses débitos. O passivo acumulado introduziu certa rigidez na necessidade de geração de divisas, e comprometeu os fluxos do presente com o pagamento das rendas recebidas no passado.

Com o crescimento econômico as obrigações crescem pelo aumento das importações de bens e serviços. Podem crescer também pelas facilidades de obter financiamentos nos momentos de farta liquidez internacional. Este, aliás, é um aspecto interessante que permeia toda a história econômica brasileira e faz com que suas transações econômicas com o resto do mundo alternem momentos de otimismo e crises.

\footnotetext{
${ }^{5}$ Dados disponíveis em http://www.bcb.gov.br, acesso em 30/03/04
} 
Parece que tudo vai bem enquanto existe liquidez internacional e se consegue captar recursos no exterior com facilidade para financiar os déficits em transações correntes. A sucessão de saldos deficitários dessa fase forma o estoque da dívida externa, que implica a necessidade de remessa de rendas futuras, na forma de juros e lucros. As crises surgem nas fases de contração da liquidez e conseqüente dificuldade de financiar o déficit. Nessas etapas a escassez de divisas torna-se o maior empecilho ao crescimento econômico até porque o enfrentamento da crise resulta em acordos com o FMI (Fundo Monetário Internacional), que induz ajuste das contas públicas que, por sua vez, leva ao declínio no ritmo de crescimento econômico, até que surja novo ciclo de liquidez internacional.

Desde 2001 o país voltou a ter superávit comercial e em 2003 chegou a apresentar superávit em transações correntes de US \$ 4 bilhões. Isso foi possível porque o valor das exportações cresceu quase $10 \%$ a.a. a partir de 2000, mas também porque, com crescimento econômico irrisório acumulando apenas $3 \%$ em 3 anos $^{6}$, o valor das importações de bens e serviços teve redução superior a $5 \%$ a.a. Quando a economia voltar a crescer a taxas que resultem em melhoria da qualidade de vida da população brasileira, as importações também crescerão, trazendo de volta os déficits em transações correntes, bem como a possibilidade de crises no balanço de pagamentos, se o comércio de bens e serviços não for capaz de prover as divisas necessárias para honrar os compromissos externos.

\section{O comércio agrícola brasileiro}

Uma das implicações naturais do desenvolvimento econômico é a queda da importância relativa da agricultura na atividade econômica. No Brasil esse processo foi acelerado pela adoção do modelo de substituição de importações e, entre 1950 e 1990, a participação do setor no PIB caiu à taxa média anual de 2,3\%. No começo da década de 1950 a agricultura representava $1 / 4$ do PIB brasileiro a preços básicos e chegou ao mínimo de $7,6 \%$ em 1993. Daí em diante o setor voltou a crescer mais que o

\footnotetext{
${ }^{6}$ A taxa de crescimento real do PIB foi de 1,3\% em 2001, de 1,9\% em 2002 e de $-0,2$ em 2003. Em termos per capita os percentuais são 0,0\%, 0,6\% e -1,5\%, respectivamente, totalizando decréscimo de $0,9 \%$ nesses 3 anos (IBGE, 2004).

${ }^{7}$ O valor adicionado a preços básicos foi estimado em R $\$ 1.199$ trilhões para 2002 e R\$ 1.356 trilhões em 2003, anos em que a participação da agropecuária foi de 8,7\% e $10,2 \%$, respectivamente (IBGE, 2004).
} 
restante da economia ultrapassando $10 \%$ em $2003^{7}$.

Desde o final da década de 1940 quando a CEPAL passou a advogar a substituição de importações como estratégia de desenvolvimento para os países periféricos o problema estava em depender de exportações de produtos primários, para pagar pelas importações de bens industrializados. A disparidade na elasticidade-renda da demanda por importações (alta) e exportações (baixa) daria causa à deterioração dos termos de troca e conseqüentes dificuldades do balanço de pagamentos das economias periféricas. Como a demanda por produtos primários também tem baixa elasticidade-preço, se o esforço do conjunto dos países para aumentar o volume exportado excedesse o aumento da renda dos países centrais, haveria tal baixa dos preços que o valor das exportações poderia vir a ser menor do que antes ${ }^{8}$.

Já não se pode dizer que a dinâmica econômica brasileira seja impulsionada por suas exportações para os países centrais, até porque, até recentemente o valor das exportações brasileiras representava menos de $10 \%$ do PIB. Além disso, na atualidade, é a demanda dos países em desenvolvimento que mais cresce no mundo. Entre 1990 e 2002 as importações dos países da OCDE (Organização para Cooperação e Desenvolvimento Econômico) cresceram 5,3\% a.a. enquanto as dos demais países cresceram $6,8 \%$ a.a. Com isso as importações mundiais registraram taxa anual de crescimento de 5,7\% (Tabela 2).

Tabela 2. Taxa anual de crescimento do comércio agrícola e total entre 1990-2002(1) (em porcentagem)

\begin{tabular}{lcccccc}
\hline & \multicolumn{2}{c}{ Agrícola } & & \multicolumn{2}{c}{ Total } \\
\cline { 2 - 3 } \cline { 5 - 6 } & Importação & Exportação & & Importação & Exportação \\
\hline Brasil & 3,7 & 5,8 & & 9,4 & 5,8 \\
OCDE & 1,7 & 1,9 & & 5,3 & 5,0 \\
Outros $\left({ }^{2}\right)$ & 2,9 & 3,0 & & 6,8 & 7,9 \\
Mundo & 2,0 & 2,3 & & 5,7 & 5,8 \\
\hline
\end{tabular}

(') Comparação entre as médias dos triênios 1990-92 e 2000-02

$\left.{ }^{2}\right)$ Exclusive OCDE

Fonte de dados básicos: FAOSTAT database

\footnotetext{
${ }^{8}$ Prebisch inicialmente argumentou que a deterioração dos termos de troca das economias periféricas decorria da dinâmica dos ciclos econômicos. Posteriormente complementou sua análise incluindo as diferenças de elasticidade-renda como causas (PREBISCH, 1949 e 2000). Como SINGER (1950) chegou chegaram a conclusões semelhantes em trabalhos desenvolvidos concomitantemente, e a tese ficou conhecida como Prebisch-Singer.
} 
Quanto à dependência da exportação de produtos de baixa elasticidade-preço e renda, não é seguro dizer que os argumentos de Prebisch não mais procedem. Para o Brasil, pelo menos as seguintes tendências tornam suas preocupações ainda pertinentes:

1. A demanda mundial por produtos agrícolas cresce menos que a dos produtos industrializados;

2. O Brasil aumentou a dependência de produtos agrícolas como fonte de divisas;

3. O relativo sucesso das exportações brasileiras mais se deve ao aumento das quantidades exportadas; e

4. A evolução das relações de troca tem sido desfavorável ao Brasil

Como evidência da primeira asserção, podem ser utilizados os dados de importações mundiais da FAO (Organização das Nações Unidas para a Alimentação e Agricultura), disponíveis para o período 1961-2002. Nesse período todo o valor das importações mundiais cresceu à taxa de 10,7\%a. a. Esse número é resultado de crescimento anual de 7,3\% das importações agrícolas e de $11,3 \%$ das importações dos produtos não-agrícolas.

Dividindo-se a série em subperíodos de aproximadamente 20 anos, observa-se que as diferenças de tendência já eram observadas antes de 1980. De 1961 a 1980 as importações totais cresceram 15,9\% a.a., as agrícolas $11,5 \%$ a.a. e as não-agrícolas 17,0\% a.a. Depois de 1980 o crescimento do total das importações mundiais caiu para 6,8\%a.a., enquanto os produtos agrícolas cresceram 3,8\% a.a. (Tabela 3).

Tabela 3. Taxa anual de crescimento das importações mundiais, 1961-2002 (1)

\begin{tabular}{lccc}
\hline Produto & $1961-80$ & $1980-2002$ & $1961-2002$ \\
\hline Agrícola & 11,5 & 3,8 & 7,3 \\
Não-agrícola & 17,0 & 7,1 & 11,3 \\
Total & 15,9 & 6,8 & 10,7 \\
\hline
\end{tabular}

$\left({ }^{1}\right)$ Resultados obtidos a partir de regressão log-linear com nível de significância de $1 \%$ Fonte de dados básicos: FAOSTAT database

Para argumentar sobre a segunda asserção, além dos próprios dados da FAO foram utilizados os da FUNCEX (Fundação Centro de Estudos do Comércio Exterior), disponíveis desde 1974․ Pelos dados da FUNCEX, a participação da agricultura nas exportações, da casa dos $15 \%$ no início 
da série caiu para menos de 5\% entre 1981 e 1996 e voltou a superar este percentual nos anos finais. A mínima participação da agricultura nas exportações foi de 2,9\% observada em 1991. Daí em diante as exportações do setor oscilaram, mas com nítida tendência de crescimento, alcançando 7,5\% em 2003 (Tabela 4).

Os dados da FAO também mostram quebra de tendência por volta de 1991. Entre 1974 e 1977 a participação das exportações agrícolas se situava em torno de 60\%. Entre 1977 e 1991 declinou nitidamente, atingindo $25 \%$ entre 1991 e 1993 . Daí em diante assumiu um novo patamar, entre 28 e $30 \%$, se desconsiderado o ano de 2000 .

O crescimento das exportações agrícolas aumentou a importância relativa do setor no PIB. A taxa de crescimento do PIB agropecuário foi inferior à do PIB total em apenas 2 anos, 1997 e 1998. As diferenças são mais acentuadas nos últimos 5 anos da série, destacando-se 2003, ano em que o PIB teve decréscimo de $0,2 \%$ em relação ao ano anterior enquanto a agricultura cresceu $6 \%$, e sua participação no PIB aumentou de $8,7 \%$ para $10,2 \%$. Tomando por base 1990, até 2003 a economia brasileira teve crescimento acumulado de $34 \%$ enquanto o setor agropecuário acumulou $57 \%$ (Tabela 4).

O conjunto dessas informações sobre a agricultura brasileira, mostrando sua maior participação no PIB e nas exportações pode ser entendido como sucesso para o setor. No entanto, sob o ponto de vista do conjunto da economia, essa mesma evolução caracteriza aumento da vulnerabilidade externa do país. Este processo pode ser examinado segundo o enfoque desenvolvido por FAJNZYLBER (1991). Segundo este autor, um país está vulnerável no comércio quando diminui a participação nas importações mundiais de um produto com importância crescente na sua pauta de exportação ${ }^{10}$. Nesse sentido a agricultura brasileira, no agregado, está em posição de vulnerabilidade porque a demanda internacional por produtos agrícolas cresce menos que a dos demais produtos, enquanto o Brasil vem aumentando sua participação nesse mercado.

\footnotetext{
${ }^{9}$ A FUNCEX emprega a classificação da matriz insumo-produto do IBGE para definir a agricultura onde são enquadrados como agrícolas apenas os produtos in natura. A FAO incorpora produtos agrícolas processados.

${ }^{10}$ FAJNZYLBER (1991) analisa as exportações confrontando crescimento das importações dos países industrializados e crescimento das exportações do país. Se ambos crescem caracteriza uma situação ótima, se ambos diminuem, caracteriza retrocesso. Existem oportunidades perdidas quando as importações dos industrializados crescem e as exportações do país diminuem. Vulnerabilidade é crescer exportações quando as importações estão se contraindo.
} 
A classificação de FAJNZYLBER (1991), aplicada à agricultura brasileira por CARVALHO (2002) para o período 1988-99, enquadrou 63,7\% do valor das exportações agrícolas brasileiras na situação de vulnerabilidade ${ }^{11}$.

Pode-se analisar a vulnerabilidade também pelo enfoque da variabilidade do valor das exportações, uma vez que um aspecto básico da sustentabilidade do crescimento econômico de um país é sua segurança com relação aos ingressos de divisas para honrar os compromissos externos. Nesse aspecto, contar com a agricultura não é o melhor caminho porque, embora o comércio como um todo tenha apresentado evolução bastante instável nas últimas décadas, a instabilidade do comércio agrícola é sistematicamente superior.

A análise do total das importações mundiais no período 1961-2002, a partir dos dados da FAO, permite verificar que a taxa de crescimento agrícola apresentou coeficiente de variação de $134 \%$ contra 92\% para os demais produtos. O cálculo para o crescimento das exportações brasileiras resultou em $201 \%$ para os produtos agrícolas e $120 \%$ para os demais produtos.

As informações produzidas pela FUNCEX permitem separar os efeitos das variabilidades de preços e das quantidades exportadas. As taxas de crescimento dos preços agrícolas, em particular, apresentaram coeficiente de variação muito elevado (11.740\%), resultado de alternâncias de períodos de altas e baixas ${ }^{12}$. Os preços dos manufaturados também apresentam elevado coeficiente de variação $(365,6 \%)$, mas equivalente a cerca de $3 \%$ do coeficiente da agricultura (Tabela 5 ).

${ }^{11}$ A classificação resultou em 15,3\% do valor exportado em situação de retrocesso, 11,3\% em situação ótima e 9,6\% como oportunidades perdidas.

12 Na média do período 1974-2003 a taxa de crescimento dos preços agrícolas foi de apenas $0,1 \%$ a.a. contra $1,9 \%$ a.a. para os produtos manufaturados. 
Tabela 4. Taxas de crescimento do Produto Interno Bruto (PIB) total e agrícola, e participação da agricultura no PIB e nas exportações brasileiras, 1974-2003

\begin{tabular}{|c|c|c|c|c|c|}
\hline \multirow{3}{*}{ Ano } & \multicolumn{2}{|c|}{ PIB $\left({ }^{1}\right)$} & \multicolumn{3}{|c|}{ Participação da agricultura $\left({ }^{2}\right)$} \\
\hline & \multirow{2}{*}{ Total } & \multirow{2}{*}{ Agrícola } & \multirow{2}{*}{ PIB } & \multicolumn{2}{|c|}{ Exportações } \\
\hline & & & & FUNCEX & FAO \\
\hline 1974 & 57,4 & 57,4 & 12,2 & 15,4 & 60,8 \\
\hline 1975 & 60,4 & 61,2 & 11,5 & 14,9 & 55,8 \\
\hline 1976 & 66,6 & 62,7 & 11,7 & 13,2 & 60,0 \\
\hline 1977 & 69,9 & 70,3 & 13,6 & 12,3 & 62,0 \\
\hline 1978 & 73,3 & 68,5 & 11,2 & 6,7 & 52,4 \\
\hline 1979 & 78,3 & 71,7 & 10,8 & 6,0 & 46,3 \\
\hline 1980 & 85,5 & 78,5 & 10,9 & 5,5 & 46,3 \\
\hline 1981 & 81,9 & 84,8 & 11,2 & 4,6 & 41,3 \\
\hline 1982 & 82,6 & 84,6 & 9,7 & 3,9 & 39,8 \\
\hline 1983 & 80,1 & 84,2 & 12,5 & 4,8 & 41,1 \\
\hline 1984 & 84,5 & 86,4 & 13,8 & 4,1 & 38,6 \\
\hline 1985 & 91,1 & 94,7 & 12,6 & 6,0 & 36,7 \\
\hline 1986 & 97,9 & 87,1 & 12,1 & 4,0 & 34,2 \\
\hline 1987 & 101,4 & 100,1 & 10,8 & 4,7 & 32,6 \\
\hline 1988 & 101,3 & 101,0 & 11,4 & 3,9 & 29,3 \\
\hline 1989 & 104,5 & 103,9 & 9,8 & 4,7 & 27,7 \\
\hline 1990 & 100,0 & 100,0 & 8,1 & 4,4 & 27,9 \\
\hline 1991 & 101,0 & 101,4 & 7,8 & 2,9 & 25,2 \\
\hline 1992 & 100,5 & 106,3 & 7,7 & 3,7 & 25,4 \\
\hline 1993 & 105,4 & 106,3 & 7,6 & 3,9 & 25,1 \\
\hline 1994 & 111,6 & 112,0 & 9,9 & 4,3 & 28,8 \\
\hline 1995 & 116,3 & 116,6 & 9,0 & 2,9 & 28,7 \\
\hline 1996 & 119,4 & 120,2 & 8,3 & 3,5 & 30,0 \\
\hline 1997 & 123,3 & 119,2 & 8,0 & 5,8 & 30,2 \\
\hline 1998 & 123,4 & 120,8 & 8,2 & 5,5 & 29,8 \\
\hline 1999 & 124,4 & 130,8 & 8,3 & 4,6 & 28,8 \\
\hline 2000 & 129,9 & 133,6 & 8,0 & 5,1 & 23,2 \\
\hline 2001 & 131,5 & 141,3 & 8,4 & 6,5 & 27,6 \\
\hline 2002 & 134,1 & 149,2 & 8,7 & 6,5 & 27,7 \\
\hline 2003 & 133,8 & 156,6 & 10,2 & 7,5 & 28,6 \\
\hline
\end{tabular}

(1) Índice: $1990=100$

(2) Em porcentagem

Fonte: Estimado pelos autores com base em dados da FAO, FUNCEX e IBGE 
Tabela 5. Coeficiente de variação da taxa de crescimento das exportações, Brasil, 1974-2003( $\left.{ }^{1}\right)$ (em porcentagem)

\begin{tabular}{lccc}
\hline & Agrícola & Manufaturado & Total \\
\hline Preço & $11.740,0$ & 365,6 & 507,8 \\
Quantidade & 297,4 & 134,7 & 134,2 \\
Valor & 307,0 & 147,1 & 134,5 \\
\hline
\end{tabular}

(1) Calculado a partir da variação percentual dos índices de preço, quantum e valor das exportações.

Fonte de dados básicos: FUNCEX, disponível em: http://www.ipeadata.gov.br

A diferença de variabilidade das taxas de crescimento da quantidade exportada é menos drástica que a dos preços, mas ainda assim expressiva. O coeficiente de variação da agricultura $(297,4 \%)$ supera o dobro do dos produtos manufaturados $(134,7 \%)$.

Como preços e quantidades agrícolas têm maior variabilidade que os manufaturados, naturalmente o valor das exportações também tem, e essa é uma das causas importantes das preocupações com a dependência desses produtos como fonte de divisas. O período 1998 a 2000 dá um exemplo claro disso. Dois anos de quedas nos preços seguidos por um outro de redução da quantidade exportada, interromperam uma série de anos de crescimento da participação da agricultura nas exportações agrícolas brasileiras (Tabela 4).

A variabilidade das receitas de exportação é mais acentuada quanto maior for o grau de concentração das exportações e esse é um dos problemas do comércio agrícola brasileiro. Na média do triênio 2000-2002 apenas 10 produtos responderam por $79,3 \%$ das divisas obtidas pelo setor sendo que dois deles, soja em grão e torta de soja, foram responsáveis por $30,4 \%$.

O problema da concentração das exportações agrícolas é antigo e não tem apresentado tendência de melhora. Estimativas do índice de Gini resultaram em 0,93 e 0,94 para as médias dos triênios 1980-1982 e 1990-1992, respectivamente (SILVA e CARVALHO, 1999). Nova estimativa para 2000-2002 resultou também em 0,94 indicando persistência de elevado grau de concentração dado que o grau máximo é atingido quando o índice é igual a 1.

A constatação da terceira asserção, de que o sucesso das exportações agrícolas brasileiras mais se deve ao aumento das quantidades, pode ser 
obtida dos dados da FAO e da FUNCEX. A partir da média dos índices das exportações para o período 1974 a 1980, foram comparados os índices de preço, quantidade e valor para as médias dos qüinqüênios seguintes. Dessa comparação pode-se observar que o valor total das exportações brasileiras vem apresentando crescimento bastante acelerado e persistente de forma que 20 anos depois passou a corresponder ao quádruplo do valor observado na segunda metade da década de 1980 e no triênio 2001-2003 ultrapassou o quíntuplo (Tabela 6).

Tabela 6. Evolução das exportações por tipo de produto, Brasil, 1974-2003 (média 1974-1980 = 100)

\begin{tabular}{llrrrrr}
\hline Produto & Índice & 1981-1985 & $1986-1990$ & $1991-1995$ & $1996-2000$ & $2001-2003$ \\
\hline \multirow{2}{*}{ Agrícola (FAO)a } & Preço & 94,6 & 88,3 & 86,6 & 82,4 & 61,4 \\
& Quantidade & 139,7 & 138,0 & 168,6 & 249,7 & 384,7 \\
& Valor & 132,3 & 121,0 & 147,0 & 202,9 & 237,4 \\
\hline \multirow{2}{*}{ Agropecuário } & Preço & 91,3 & 86,6 & 78,6 & 83,3 & 68,8 \\
(FUNCEX) & Quantidade & 101,3 & 124,6 & 146,2 & 252,6 & 524,2 \\
& Valor & 94,4 & 110,2 & 118,1 & 213,1 & 375,9 \\
\hline \multirow{4}{*}{ Manufaturados } & Quantidade & 229,3 & 285,4 & 368,7 & 452,5 & 609,9 \\
& Preço & 125,8 & 131,3 & 140,4 & 147,5 & 132,4 \\
& Valor & 272,1 & 356,6 & 488,7 & 629,3 & 764,4 \\
\hline \multirow{2}{*}{ Total } & Preço & 112,5 & 116,9 & 118,5 & 123,6 & 107,6 \\
& Quantidade & 173,0 & 207,1 & 271,8 & 341,5 & 487,2 \\
& Valor & 190,1 & 238,7 & 315,8 & 410,7 & 514,6 \\
\hline
\end{tabular}

${ }^{a}$ Dados disponíveis até 2002 .

Fonte de dados básicos: FAO e FUNCEX, disponíveis em http://fao.org e http://www.ipeadata. gov.br, acesso em abril de 2004

O índice de preços do conjunto das exportações brasileiras mostrou evolução moderada no período, mas em nenhum qüinqüênio esteve abaixo da média de 1974-80. Quanto aos índices da agropecuária a situação é inversa: tanto a série da FUNCEX, que considera apenas os produtos agrícolas in natura, como a da FAO, que engloba também os produtos manufaturados, em nenhum qüinqüênio esteve acima da média de 1974-80. Nesse inicio de milênio registra-se o período de preços mais desfavoráveis, com índice médio igual a 68,8 pelos dados da FUNCEX e 61,4 pelos da FAO. 
De 2001 a 2003 é também o período em que a agricultura contabilizou maior ingresso de divisas, equivalente a quase 4 vezes o valor de 1974-80 pelos dados da FUNCEX. Se os preços caíram e a receita cresceu, naturalmente isso se deve a um grande crescimento das quantidades exportadas pelo setor, da ordem de $424 \%$ sobre o início da série.

Os dados da FUNCEX permitem observar também que a evolução dos preços dos produtos manufaturados foi bem mais favorável que a dos agrícolas, com crescimento em todos os qüinqüênios desde a década de 1980. Os últimos 3 anos foram os mais desfavoráveis: da média de 147,5 , no qüinqüênio 1996-2000, o índice de preço caiu para 132,4 . No entanto, como a quantidade exportada continuou crescendo em ritmo acelerado, de 2001 a 2003, o valor das exportações dos manufaturados cresceu em $21 \%$ em relação ao qüinqüênio anterior.

Observe-se que o índice de preços do setor agropecuário também caiu: de 83,3 no qüinqüênio 1996-2000 para 68,8 no triênio 2001-2003, mas o crescimento da quantidade exportada foi tão acelerado que o valor das exportações foi incrementado em 76,4\% .

Uma vez que a agricultura vem elevando sua participação nas exportações e seus índices de preços apresentam tendência decrescente, parte do esforço exportador vem sendo neutralizada pela queda dos preços. Este é o núcleo da quarta asserção, que pode ser atestada pela análise do comportamento dos preços dos produtos importados, para concluir sobre a evolução das relações de troca do país com o resto do mundo.

Por relações de troca entende-se a razão entre os preços dos produtos exportados e o preço dos produtos importados. Neste trabalho confrontamos os preços das exportações aos preços das importações de produtos agropecuários $\left(P_{X} / P_{M}\right.$ agropecuária) e os preços das exportações de produtos agropecuários aos preços das importações totais $\left(P_{X}\right.$ agropecuária $/ P_{M}$ total) para o período 1974-2003.

Para minimizar a influência da base de comparação sobre os resultados, optou-se pela média da série dos 30 anos disponíveis. Desse procedimento resultou que a evolução das relações de troca da própria agropecuária, que confronta a evolução de suas exportações e importações, foi predominantemente favorável ao Brasil. Em 17 anos os preços dos produtos exportados pelo setor superaram o dos importados (índice superior a 100), sendo que os últimos 7 anos estão enquadrados nessa situação (Figura 1). 
O confronto dos preços dos produtos agrícolas exportados aos preços do total das importações mostra que a década de 1970 foi o período mais favorável. Daí em diante em apenas 5 anos as relações de troca ultrapassaram ligeiramente a média da série, destacando-se o triênio 1996-98 quando alcançou 110\% . De 1999 a 2003 as relações de troca da agricultura têm sido bastante desfavoráveis ao país, com índice médio igual a 87 .

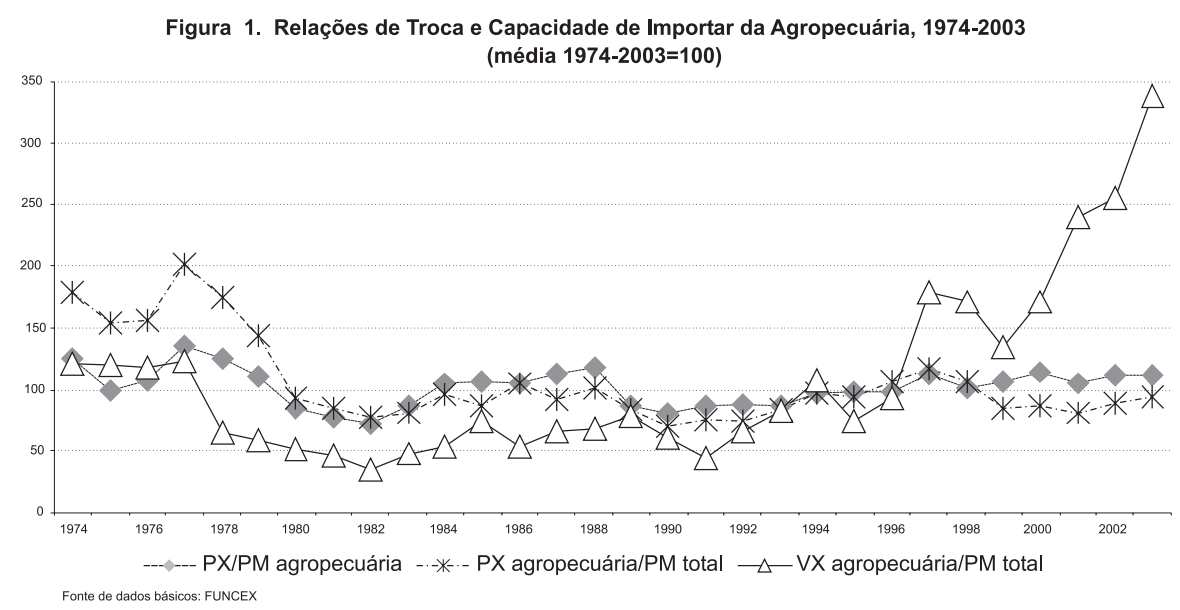

Para reforçar o argumento pode-se estimar o índice da capacidade de importar, que é a razão entre o valor das exportações agropecuárias e o índice de preços do total das importações (VX agropecuária/PM total). Na Figura 1 é visível a evolução crescente desse índice a partir de 1991, chegando a 337 em 2003. Como a evolução das relações de troca esteve predominantemente abaixo de 100, evidencia, mais uma vez, que o relativo sucesso das exportações agrícolas brasileiras se deve ao aumento das quantidades exportadas.

\section{Considerações finais}

Se houver capacidade ociosa o comércio exterior pode promover o crescimento econômico pelo efeito multiplicador das exportações sobre a economia local. O tamanho desse efeito depende, entre outras coisas, dos encadeamentos do setor exportador com os demais setores. Quanto mais dinâmica e diversificada for a pauta de exportação, maior o grau de 
envolvimento entre setores e maiores as possibilidades de gerar estímulos ao crescimento do mercado interno.

O crescimento econômico, por sua vez, induz o aumento das importações, e se o objetivo é crescer a economia sem endividamento externo, é necessário que as exportações provejam as divisas necessárias para pagar pelas importações de bens e serviços.

No passado argumentou-se que o predomínio de produtos primários nas exportações levava à deterioração dos termos de troca e conseqüente tendência estrutural ao desequilíbrio no balanço de pagamentos. Esse assunto, objeto de grande polêmica ao longo de décadas, volta a ter relevância para o Brasil na medida que a agricultura vem sendo seu setor mais dinâmico, com crescimento da participação no PIB e nas exportações ${ }^{13}$. Como o país acumulou grande passivo externo, a geração de divisas é prioridade máxima, e contar crescentemente com a agricultura para honrar seus compromissos acrescenta graus de vulnerabilidade à economia brasileira.

Uma das razões é que a agricultura é um setor em declínio no comércio mundial: a taxa de crescimento das importações agrícolas mundiais é bem menor que a dos demais produtos, tendência acentuada a partir da década de 1980. Além disso, as importações agrícolas dos países mais desenvolvidos apresentam tendência de redução ainda mais acentuada. Em conseqüência, as exportações brasileiras mais crescem para os mercados dos países em desenvolvimento, que nem sempre têm capacidade sustentada de pagamentos.

Outro aspecto da vulnerabilidade decorrente da dependência de

\footnotetext{
${ }^{13}$ Muitos autores questionaram as conclusões da CEPAL acerca da deterioração dos termos de troca dos produtos primários. Grande parte das críticas se baseava na comprovação empírica dado que em épocas diferentes e tomando outras bases de comparação chegava-se a outros resultados. O tema ainda desperta interesse dos pesquisadores, como é o caso de GRILLI e YANG (1988) que produziram minucioso trabalho empírico relacionando preço das commodities ao dos produtos manufaturados para o período 1900 a 1986 . Constataram tendência de queda dos preços relativos à taxa de 0,5\%a.a. para todas as commodities e de 0,6\%a.a. quando excluem petróleo. BLOCH e SAPSFORD (1997) encontraram evidências dos efeitos negativos sobre os termos de troca dos produtos primários após a II Guerra Mundial, conforme hipótese de Prebisch-Singer. OCAMPO e PARRA (2003) analisaram as séries de commodities e de produtos manufaturados para todo o século XX, concluindo que as commodities tiveram deterioração dos termos de troca ao longo do século XX, embora não contínua nem regular. Concluíram também, que no agregado, os preços das matérias primas apresentaram tendência de redução real da ordem de $1 \%$ a.a.
} 
produtos agrícolas está relacionado à variabilidade. O confronto dos coeficientes de variação das taxas de crescimento do valor das exportações mundiais de produtos agrícolas e dos demais produtos mostra que a variabilidade destes é bem menor, ou seja, é menos seguro contar com a agricultura como fonte de divisas.

No caso brasileiro foi possível estimar essas diferenças entre produtos agrícolas e manufaturados de onde se concluiu que são ainda mais acentuadas. Entre 1974 e 2003 a variabilidade do crescimento das exportações agrícolas foi o dobro da dos manufaturados. Ao comportamento dos preços agrícolas cabe a maior responsabilidade pelas diferenças, embora as quantidades também tenham contribuição expressiva. Acrescente-se que grande parte dessa variabilidade se deve ao elevado grau de concentração do comércio agrícola brasileiro, dado que apenas 10 produtos respondem por quase $80 \%$ do valor exportado.

Um outro aspecto importante que as estatísticas disponíveis permitiram ressaltar é que o sucesso das exportações agrícolas no período recente é devido ao aumento do volume exportado. Os preços agrícolas vêm mostrando tendência de baixa e nos últimos 5 anos o índice das relações de troca que compara preços das exportações agrícolas e preços de todos os produtos importados pelo Brasil esteve bem abaixo da média dos últimos 30 anos.

A literatura econômica denomina crescimento empobrecedor à situação em que o aumento de produção acontece predominantemente no setor exportador e provoca deterioração dos termos de troca de tal magnitude que pode reduzir a renda real do país. A possibilidade é maior quando as elasticidades da demanda mundial pelas mercadorias exportadas são muito baixas. Essa descrição parece apropriada para o Brasil da atualidade, onde a atividade econômica vem sendo impulsionada pelo aumento das exportações de produtos agrícolas, de notória inelasticidade, os termos de troca estão desfavoráveis e o valor das exportações só é crescente devido à expansão das quantidades exportadas.

\section{Referências bibliográficas}

BLOCH, Harry; SAPSFORD, David. Some estimates of Prebisch and Singer Effects on the terms of trade between primary producers and manufacturers. World Development, V. 25, n. 11, p. 1873-1884, 1997. 
CARVALHO, Maria A. Comércio agrícola e vulnerabilidade externa brasileira. Agricultura em São Paulo, São Paulo, v. 49, t. 2, p. 55-69, 2002. FAJNZYLBER, F. Inserción internacional e innovación institucional. $\underline{R e-}$ vista de La Cepal, Santiago de Chile, n. 44, p. 149-78, Ago. 1991.

IBGE. PIB 2003 foi de $R \$ 1,5$ trilhão e renda per capta fica em $R \$ 8.565$. Disponível em: < http://www.ibge.gov.br/home/presidencia/noticias/ pdf/31032004pib.pdf > . Acesso em 1 abr. 2004.

GRILLI, Enzo R.; YANG, Maw C. Primary commodity prices, manufactured goods prices, and the terms of trade of developing countries: what the long run shows. The World Bank Economic Review, vol. 2, n. 2, 1988, p. 1-47.

MARQUEZ, Jaime. Bilateral trade elasticities, Review of Economics and Statistics, V. 72, p. 70-77, 1990.

NAÇÕES UNIDAS. Relações de troca post-guerra entre países subdesenvolvidos e países industrializados. Revista Brasileira de Economia. RJ, 3(3):15-46, set. 1949.

OCAMPO, José A.; PARRA, Maria A. Returning to na eternal debate: the terms of trade for commodities in the twentieth century. Santiago: CEPAL, Feb. 2003 (Informes y estudios especiales, 5), Disponível em: < http:// www.eclac.cl/publicaciones/Secretaria Ejecutiva/3/LCL1813PI/lcl1813i. pdf > . Acesso em 2 mar. 2004.

PREBISCH, Raúl. O desenvolvimento econômico da América Latina e seus principais problemas. Revista Brasileira de Economia. RJ, 3(3):47111, set. 1949 .

- O desenvolvimento econômico da América Latina e seus principais problemas. Revista Brasileira de Economia. Rio de Janeiro, v. 3, n. 3, p.47-111, set. 1949.

. Problemas teóricos e práticos do crescimento econômico. In: BIELSCHOWSKY, Ricardo (org.). Cinqüenta anos de pensamento na CEPAL. Rio de Janeiro: Record, 2000, v. 1. p. 179-215

SILVA, César R. L.; CARVALHO, Maria A. Concentração do comércio agrícola brasileiro. Preços Agrícolas, Piracicaba, v. 14, n. 157, p. 4-8, 1999. 
SINGER, Hans. The distribution of gains between investing and borrowing countries. American Economic Review, v. 40, n.2, p. 473-485, May 1950.

VASCONCELLOS. Marco A. S. de; GREMAUD, Amaury P.; TONETO JR., Rudinei. Economia Brasileira Contemporânea. São Paulo, Editora Atlas S.A., 1999. 